\title{
Mismatch negativity and neural adaptation: Two sides of the same coin. Response: Commentary: Visual mismatch negativity: a predictive coding view
}

\author{
Gábor Stefanics ${ }^{1,2 *}$, Jan Kremláček ${ }^{3}$ and István Czigler ${ }^{4}$ \\ ${ }^{1}$ Translational Neuromodeling Unit, Institute for Biomedical Engineering, University of Zurich and ETH Zurich, Zurich, \\ Switzerland, ${ }^{2}$ Laboratory for Social and Neural Systems Research, Department of Economics, University of Zurich, Zurich, \\ Switzerland, ${ }^{3}$ Faculty of Medicine in Hradec Králové, Department of Pathological Physiology, Charles University in Prague, \\ Hradec Králové, Czech Republic, ${ }^{4}$ Research Center for Natural Sciences, Institute of Cognitive Neuroscience and \\ Psychology, Hungarian Academy of Sciences, Budapest, Hungary
}

Keywords: mismatch negativity (MMN, vMMN), stimulus-specific adaptation, refractoriness, repetition suppression, habituation, modeling

\section{A Commentary on}

Refractoriness about adaptation by O'Shea, R. P. (2015). Front. Hum. Neurosci. 9:38. doi: 10.3389/fnhum.2015.00038

OPEN ACCESS

Edited by:

Klaus Gramann,

Berlin Institute of Technology,

Germany

Reviewed by:

Erich Schröger

University of Leipzig, Germany

Stefan Berti,

Johannes Gutenberg University

Mainz, Germany

*Correspondence:

Gábor Stefanics

stefanics@biomed.ee.ethz.ch

Received: 30 November 2015

Accepted: 11 January 2016

Published: 29 January 2016

Citation:

Stefanics G, Kremláček J and Czigler I (2016) Mismatch negativity and neural adaptation: Two sides of the same coin. Response: Commentary: Visual mismatch negativity: a predictive coding view.

Front. Hum. Neurosci. 10:13. doi: 10.3389/fnhum.2016.00013
Our recent paper (Stefanics et al., 2014) provided a comprehensive review of the visual MMN literature from a predictive coding perspective. We argued the MMN reflects a phenomenon consisting of multiple neural processes underlying the initial response to rare, unpredicted stimuli and the attenuation of this response over subsequent stimulus repetitions. We think repetition suppression (RS) is an important process of the compound mismatch phenomenon. In our review we often referred to the contribution of the repetition effect to the MMN as "refractoriness" and highlighted that predictive coding offers a unified framework to explain the multiple mismatch processes.

O'Shea (2015) argued that a "better term for refractoriness is 'adaptation' [and that] adaptation ought to be harmonized into any complete MMN explanation." O'Shea concluded that "replacing 'refractoriness' in the MMN vocabulary with adaptation terms and searching for a rapprochement between adaptation and MMN could bring considerable explanatory benefits."

The term "refractoriness" was originally used in the MMN field to describe response attenuation for repeated events, linked to sensory memory formation (Näätänen and Picton, 1987). The deviant-minus-standard difference caused by repetition was attributed to neuronal fatigue, as opposed to the difference caused by genuine mismatch-related responses. The MMN community considered the standard-related effects irrelevant to deviance detection. In other fields which focus on stimulus-specific adaptation (SSA) instead of deviance detection (psychophysics, cellular electrophysiology, and neuroimaging) RS is attributed to active memory processes. Thus, there are important differences in where the emphasis of RS-related research lies in the MMN and other fields.

We agree with O'Shea (2015) that harmonizing adaptation into any theoretical treatment of the MMN is necessary and beneficial. In fact, we aimed to contribute to the harmonization process by discussing not only MMN but also adaptation in our review. Replacing refractoriness in the MMN vocabulary with adaptation terms would help the field acknowledge that deviance detection is intricately linked to the process of regularity extraction, which in turn is linked to adaptation or 
RS. Nevertheless, each of these terms is used to describe several related concepts and phenomena, and it is hard to pin one concept on one term.

In the 1980s it was common to refer to repetition effects for ERPs as refractoriness. Using this term to describe changes in scalp-recorded ERPs was perhaps not the best choice for the MMN field, because it emphasizes the passive nature of the response attenuation at the single neuron level whereas several line of evidence suggests that RS in not the result of refractorylike fatigue. However, simply replacing refractoriness in the MMN vocabulary with adaptation terms might create the false impression that network mechanisms underlying RS (Ibbotson, 2005; Grill-Spector et al., 2006) are well understood. This should be avoided, therefore harmonizing adaptation and MMN should be done with caution.

$\mathrm{RS}$ is a ubiquitous phenomenon, observed in countless experiments in several distinct fields. However, integrating results from different fields using disparate methodologies is not straightforward. For example, several attempts have been made to identify the single-cell correlates of scalp-recorded MMN. Auditory SSA is associated with midlatency potentials and is the closest known single-neuron phenomenon of MMN (Escera and Malmierca, 2014; Nelken, 2014). The magnitudes of SSA and MMN are both negatively correlated with the probability of the deviant but positively correlated with the difference between standard and deviant. However, an important difference is the earlier timing of SSA relative to MMN, which led Nelken and Ulanovsky (2007) to suggest that SSA is a correlate of change detection in the primary auditory cortex upstream of $\mathrm{MMN}$, and that $\mathrm{MMN}$ itself is a compound response of primary and higher-level cortical areas with longer response latencies.

SSA is present at nearly all stages in visual processing (Solomon and Kohn, 2014) and involves at least three mechanisms, including (1) somatic afterhyperpolarization, (2) synaptic depression due to the depletion of vesicles from the presynaptic terminal, and (3) synaptic (network) mechanisms (Kohn, 2007). Because the refractory state of a neuron after spiking is too short to be responsible for the ERP amplitude decrease after repeated stimulation and synaptic depletion also occurs only at higher stimulation rates than in MMN experiments, RS in MMN experiments likely results from network mechanisms which are not fully understood yet in the visual system.

Results of visual ERP studies of adaptation have been variable. Several studies reported attenuation of some ERP components (Schweinberger et al., 2004; Fiebach et al., 2005; Kovács et al., 2006; Harris and Nakayama, 2007; Huber et al., 2008; Caharel

\section{REFERENCES}

Andrade, G. N., Butler, J. S., Mercier, M. R., Molholm, S., and Foxe, J. J. (2015). Spatio-temporal dynamics of adaptation in the human visual system: a high-density electrical mapping study. Eur. J. Neurosci. 41, 925-939. doi: 10.1111/ejn. 12849 et al., 2009; Vizioli et al., 2010; Vakli et al., 2014). However, some of the above and other studies (Puce et al., 1999; Andrade et al., 2015) also observed repetition enhancement, or no change. Thus, ERP correlates of visual adaptation warrants further investigation.

Attempts to disentangle different processes underlying RS and change detection has led the MMN field to come up with smart experimental paradigms, such as the equiprobable control, which allows studying effects of stimulus repetition and change separately (Schröger and Wolff, 1996; Ruhnau et al., 2012). Although experimental manipulations indeed help disentangle compound processes, a principled approach might be using computational models (May and Tiitinen, 2010; Garagnani and Pulvermüller, 2011; Wacongne et al., 2012). Dynamic causal modeling (DCM) has been successfully used to compare largescale network models of MMN (Kiebel et al., 2007; Garrido et al., 2008, 2009) which incorporate hypotheses of both adaptation and change detection. Further recent modeling studies demonstrate the potential of predictive coding to provide a comprehensive explanation of MMN phenomenology (Lieder et al., 2013a). Results of Lieder et al. (2013b) suggest that the MMN reflects approximate Bayesian learning, and that the MMN-generating process adjusts a probabilistic model of the environment using prediction errors.

\section{CONCLUSION}

Using neurobiologically informed modeling frameworks which rely on Bayesian probability theory might provide rapprochement between adaptation and MMN. By focusing on computational mechanisms (Marr, 1982) instead of phenomenological description of neural responses, such an approach might lead to the emergence of a vocabulary that is abstract enough to support communication across diverse research fields which nevertheless study similar phenomena.

\section{AUTHOR CONTRIBUTIONS}

GS, JK, and IC wrote the paper.

\section{ACKNOWLEDGMENTS}

We are grateful to Marta Isabel Garrido, Adam Kohn, Falk Lieder, Israel Nelken, and Robert O'Shea for their helpful comments. IC received support from the Hungarian Research Fund (OTKA), Grant No. 1044462. JK was supported by the P37/07 (PRVOUK) program. 
research. Psychophysiology 51, 111-123. doi: 10.1111/psyp. 12156

Fiebach, C. J., Gruber, T., and Supp, G. G. (2005). Neuronal mechanisms of repetition priming in occipitotemporal cortex: spatiotemporal evidence from functional magnetic resonance imaging and electroencephalography. J. Neurosci. 25, 3414-3422. doi: 10.1523/JNEUROSCI.4107-04.2005

Garagnani, M., and Pulvermüller, F. (2011). From sounds to words: a neurocomputational model of adaptation, inhibition and memory processes in auditory change detection. Neuroimage 54, 170-181. doi: 10.1016/j.neuroimage.2010.08.031

Garrido, M. I., Friston, K. J., Kiebel, S. J., Stephan, K. E., Baldeweg, T., and Kilner, J. M. (2008). The functional anatomy of the MMN: a DCM study of the roving paradigm. Neuroimage 42, 936-944. doi: 10.1016/j.neuroimage.2008. 05.018

Garrido, M. I., Kilner, J. M., Stephan, K. E., and Friston, K. J. (2009). The mismatch negativity: a review of underlying mechanisms. Clin. Neurophysiol. 120, 453-463. doi: 10.1016/j.clinph.2008.11.029

Grill-Spector, K., Henson, R., and Martin, A. (2006). Repetition and the brain: neural models of stimulus-specific effects. Trends Cogn. Sci. 10, 14-23. doi: 10.1016/j.tics.2005.11.006

Harris, A., and Nakayama, K. (2007). Rapid face-selective adaptation of an early extrastriate component in MEG. Cereb. Cortex 17, 63-70. doi: 10.1093/cercor/bhj124

Huber, D. E., Tian, X., Curran, T., O'Reilly, R. C., and Woroch, B. (2008). The dynamics of integration and separation: ERP, MEG, and neural network studies of immediate repetition effects. J. Exp. Psychol. Hum. Percept. Perform. 34, 1389-1416. doi: 10.1037/a0013625

Ibbotson, M. R. (2005). "Physiological mechanisms of adaptation in the visual system," in Fitting the Mind to the World: Adaptation and After-Effects in HighLevel Vision, eds C. W. G. Clifford and G. Rhodes (New York, NY: Oxford University Press), 17-45.

Kiebel, S. J., Garrido, M. I., and Friston, K. J. (2007). Dynamic causal modelling of evoked responses: the role of intrinsic connections. Neuroimage 36, 332-345. doi: 10.1016/j.neuroimage.2007.02.046

Kohn, A. (2007). Visual adaptation: physiology, mechanisms, and functional benefits. J. Neurophysiol. 97, 3155-3164. doi: 10.1152/jn.000 86.2007

Kovács, G., Zimmer, M., Bankó, E., Harza, I., Antal, A., and Vidnyánszky, Z. (2006). Electrophysiological correlates of visual adaptation to faces and body parts in humans. Cereb. Cortex, 16, 742-753. doi: 10.1093/cercor/ bhj020

Lieder, F., Daunizeau, J., Garrido, M. I., Friston, K. J., and Stephan, K. E. (2013b). Modelling trial-by-trial changes in the mismatch negativity. PLoS Comput. Biol. 9:e1002911. doi: 10.1371/journal.pcbi.1002911

Lieder, F., Stephan, K. E., Daunizeau, J., Garrido, M. I., and Friston, K. J. (2013a). A neurocomputational model of the mismatch negativity. PLoS Comput. Biol. 9:e1003288. doi: 10.1371/journal.pcbi.1003288

Marr, D. (1982). Vision. San Francisco, CA: Freeman.

May, P. J. C., and Tiitinen, H. (2010). Mismatch negativity (MMN), the devianceelicited auditory deflection, explained. Psychophysiology 47, 66-122. doi: 10.1111/j.1469-8986.2009.00856.x
Näätänen, R., and Picton, T. (1987). The N1 wave of the human electric and magnetic response to sound: a review and an analysis of the component structure. Psychophysiology 24, 375-425. doi: 10.1111/j.14698986.1987.tb00311.x

Nelken, I. (2014). Stimulus-specific adaptation and deviance detection in the auditory system: experiments and models. Biol. Cybern. 108, 655-663. doi: 10.1007/s00422-014-0585-7

Nelken, I., and Ulanovsky, N. (2007). Mismatch negativity and stimulus-specific adaptation in animal models. J. Psychophysiol. 21, 214-223. doi: 10.1027/02698803.21.34.214

O’Shea, R. P. (2015). Refractoriness about adaptation. Front. Hum. Neurosci. 9:38. doi: 10.3389/fnhum.2015.00038

Puce, A., Allison, T., and McCarthy, G. (1999). Electrophysiological studies of human face perception. III: effects of top-down processing on face-specific potentials. Cereb. Cortex 9, 445-458. doi: 10.1093/cercor/9.5.445

Ruhnau, P., Herrmann, B., and Schröger, E. (2012). Finding the right control: the mismatch negativity under investigation. Clin. Neurophysiol. 123, 507-512. doi: 10.1016/j.clinph.2011.07.035

Schröger, E., and Wolff, C. (1996). Mismatch response of the human brain to changes in sound location. Neuroreport 7, 3005-3008. doi: 10.1097/00001756199611250-00041

Schweinberger, S. R., Huddy, V., and Burton, A. M. (2004). 250r: a faceselective brain response to stimulus repetitions. Neuroreport 15, 1501-1505. doi: 10.1097/01.wnr.0000131675.00319.42

Solomon, S. G., and Kohn, A. (2014). Moving sensory adaptation beyond suppressive effects in single neurons. Curr. Biol. 24, R1012-R1022. doi: 10.1016/j.cub.2014.09.001

Stefanics, G., Kremláèek, J., and Czigler, I. (2014). Visual mismatch negativity: a predictive coding view. Front. Hum. Neurosci. 8:666. doi: 10.3389/fnhum.2014.00666

Vakli, P., Németh, K., Zimmer, M., Schweinberger, S. R., and Kovács, G. (2014). Altering second-order configurations reduces the adaptation effects on early face-sensitive event-related potential components. Front. Hum. Neurosci. 8:426. doi: 10.3389/fnhum.2014.00426

Vizioli, L., Rousselet, G. A., and Caldara, R. (2010). Neural repetition suppression to identity is abolished by other-race faces. Proc. Natl. Acad. Sci. U.S.A. 107, 20081-20086. doi: 10.1073/pnas.1005751107

Wacongne, C., Changeux, J. P., and Dehaene, S. (2012). A neuronal model of predictive coding accounting for the mismatch negativity. J. Neurosci. 32, 3665-3678. doi: 10.1523/JNEUROSCI.5003-11.2012

Conflict of Interest Statement: The authors declare that the research was conducted in the absence of any commercial or financial relationships that could be construed as a potential conflict of interest.

Copyright (C) 2016 Stefanics, Kremláček and Czigler. This is an open-access article distributed under the terms of the Creative Commons Attribution License (CC BY). The use, distribution or reproduction in other forums is permitted, provided the original author(s) or licensor are credited and that the original publication in this journal is cited, in accordance with accepted academic practice. No use, distribution or reproduction is permitted which does not comply with these terms. 